\title{
Honey-containing Mouthwash
}

National Cancer Institute

\section{Source}

National Cancer Institute. Honey-containing Mouthwash. NCI Thesaurus. Code C99159.

A mouthwash containing honey with potential antimucositis activity. Upon rinsing with this mouthwash, honey modulates the production of pro-inflammatory cytokines which may kill bacteria thus potentially preventing inflammation of the mucosal membranes and may decrease chemotherapy- and/or radiation-induced oral mucositis. In addition, honey may have a protective and healing effect on the oral mucosa. 